\title{
Promoting Mental Wellbeing in Young People Aged 12-18 Years: Opportunities for Design
}

\author{
Andrea Taylor \\ The Glasgow School of Art \\ Moray, UK \\ A.Taylor@gsa.ac.uk
}

\author{
Susan Leslie \\ NHS Grampian \\ Moray, UK \\ susan.leslie@nhs.net
}

\author{
Katie Boddie \\ NHS Grampian \\ Moray, UK \\ katie.boddie@aberdeenshire.gov.uk
}

\begin{abstract}
Young people with poor mental health are more likely to have poor educational attainment, employment prospects and physical health, and mental health problems often persist into adulthood. Mental health promotion aims to elevate levels of mental wellbeing while protecting against its loss and reducing the prevalence of mental health problems. The delivery of and access to mental health promotion has evolved over recent years. This research explored the area of technology for promoting mental wellbeing in young people. The research was in two parts: focus groups with 34 young people aged 12-18 years, which identified a preference for digital sources of support; and a review of 14 apps and websites for supporting 12-18 year olds to promote their mental wellbeing, which identified significant shortfalls. The main contribution to $\mathrm{HCl}$ is new insights and opportunities for design to support young people aged 12-18 years to promote their mental wellbeing.
\end{abstract}

Mental health; mental wellbeing; mental health promotion; young people; digital technology.

\section{TERMINOLOGY}

A range of terms and definitions are used to describe mental health, reflecting different theoretical models. We therefore begin by briefly defining the terms used in this paper: mental health, mental wellbeing and mental health problems (Table 1). Our terminology is adopted from the National Health Service (NHS) health improvement agency for Scotland-NHS Health Scotland (NHS Health Scotland 2010).

Table 1: Terminology used in this paper.

\begin{tabular}{|c|l|}
\hline $\begin{array}{c}\text { Mental } \\
\text { health }\end{array}$ & $\begin{array}{l}\text { A broad concept that covers both mental } \\
\text { wellbeing and mental health problems. }\end{array}$ \\
\hline \multirow{2}{\text{Mental}}{ wellbeing } & $\begin{array}{l}\text { A concept that includes aspects of } \\
\text { subjective wellbeing (affect and life } \\
\text { satisfaction) and psychological wellbeing } \\
\text { (mastery and a sense of control, having a } \\
\text { purpose in life, a sense of belonging and } \\
\text { positive relationships with others). }\end{array}$ \\
\hline $\begin{array}{c}\text { Mental } \\
\text { health } \\
\text { problems }\end{array}$ & $\begin{array}{l}\text { A concept that refers to symptoms that } \\
\text { meet the criteria for clinical problems: } \\
\text { diagnosis of mental illness, or symptoms at } \\
\text { a sub-clinical threshold, which interfere } \\
\text { with emotional, cognitive or social function. }\end{array}$ \\
\hline
\end{tabular}

NHS Scotland draws on the dual continuum model of mental health, which posits that mental wellbeing and mental health problems are related but distinct

(C) Taylor et al. Published by BCS Learning and Development.

Proceedings of British HCl 2017 - Digital Make-Believe.

Sunderland. UK. dimensions (Keyes 2014) (Figure 1). On these continua, mental wellbeing ranges from a low (minimal) to a high (maximal) level and mental health problems from absence (minimal) through mild to severe clinically diagnosable illness (maximal). The dual continuum model recognises that good mental health is more than the absence of severe mental health problems, and that a person with a mental health problem can experience high levels of mental wellbeing and vice versa.

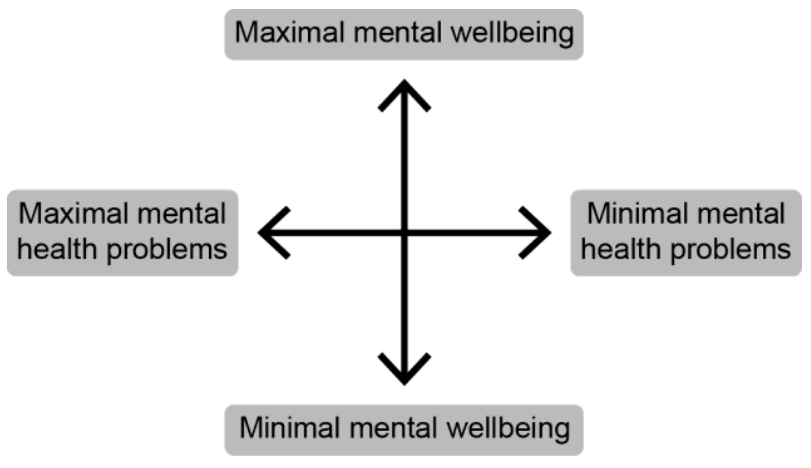

Figure 1: The dual continuum model of mental health.

\section{INTRODUCTION}

Mental health is one of the leading global public health challenges. In the UK, one in four adults and one in ten children and young people are estimated 
to experience a mental health problem in any year (Mental Health Foundation 2015). Children and young people with poor mental health are more likely to have poor educational attainment and employment prospects, social relationship difficulties, physical health and substance misuse problems, and to become involved in offending (GOV.UK 2013). Mental health problems experienced during childhood and adolescence tend to persist into adulthood (Kessler et al. 2007) and in turn, contribute to substantial economic burden due to working days lost, medical resources and reduced productivity. Indeed, mental health problems constitute the largest single source of world economic burden, with an estimated global cost of $£ 1.6$ trillion-greater than cardiovascular disease, chronic respiratory disease, cancer and diabetes on their own (Mental Health Foundation 2015). To help address the challenge of mental health, the World Health Organisation (WHO) has advised that the early stages of life present a particularly important opportunity for mental health promotion (World Health Organization 2013).

Mental health promotion refers to activity to promote mental wellbeing; to help prevent relapse or onset of mental health problems; and to improve the quality of life of those experiencing mental health problems. A range of factors determine an individual's level of wellbeing including genetic factors, environmental factors such as housing conditions and noise, socio-cultural factors such as economic status and race, life events and physical health. However, evidence indicates that the way we think about mental health (e.g. our negative or positive attitudes) and the things we do (e.g. how we cope with difficult situations) can have the greatest impact (New Economics Foundation 2008). Mental health promotion aims to change the way we think and act, and for this reason, plays an instrumental role in national mental health strategies. There is a range of ways in which mental health promotion can be delivered and accessed; for instance, it can be targeted (aimed at specific individuals and groups) or universal (aimed at all members of a population).

For example, 'Five Steps to Mental Wellbeing' is a universal and evidence-based resource that people can practice in their daily lives to improve their mental wellbeing: Connect (e.g. spend time with friends and family); Be active (e.g. engage in regular physical activity); Keep learning (e.g. try something new); Give to others (e.g. volunteer in the local community); and Be mindful (e.g. be more aware of what is taking place in the present moment) (NHS Choices 2016). In terms of targeting young people, schools are recognised as important settings. There is evidence that well designed and implemented education programmes can lead to positive wellbeing outcomes (Weare \& Nind 2011; Clarke et al. 2015). In Scotland, where this research was conducted, Health and Wellbeing is a core part of the national curriculum for schools (Curriculum for Excellence). Learning in Health and Wellbeing aims to ensure that, with appropriate guidance and support, children and young people develop the knowledge, skills and understanding necessary for mental, emotional, social and physical wellbeing (Education Scotland n.d.). Furthermore, from a young age, learners are encouraged and supported to take personal responsibility for their own health and wellbeing.

Digital technology widens the opportunities for mental health promotion. Especially among young people who have the greatest need for mental health interventions but are the least likely to seek help (Bradford \& Rickwood 2014). For most young people, digital technology is an everyday part of life. In the UK, almost all 12-15 year olds (98\%) and most $16-24$ year olds (89\%) go online, and most young people aged 12-24 years own a smartphone (Ofcom 2015; Ofcom 2016). Key benefits of digital technology for mental health promotion include: customisation and personalisation to tailor content to the individual's needs and goals; interaction techniques to increase motivation to engage in health promoting activities; a more anonymous means of accessing content, which is important given the stigma associated with mental health problems that prevents many young people seeking help (Gulliver et al. 2010); widened access for 'hard-to-reach' groups such as young people disengaged from or not attending school; and easy access to content 24 hours a day, allowing young people to exercise self-reliance and autonomy from parents (Bradford \& Rickwood 2014).

However, research studies and commercial applications have mostly focused on the prevention, treatment and recovery of mental health problems. This study explored the relatively under-researched area of digital technology for promoting mental wellbeing in young people aged $12-18$ years. The research was in two parts: focus groups with young people and a review of digital technologies for supporting young people to promote their mental wellbeing. This work contributes to the body of research within $\mathrm{HCl}$ on design for mental wellbeing. The main contributions are:

- To our knowledge, the first review of apps and websites for promoting mental wellbeing in young people aged 12-18 years.

- Findings and insights from the study that demonstrate the need for future research and design of digital technologies to support young people aged 12-18 years to promote their mental wellbeing.

- Translation of the presented findings and insights into opportunities for research and design to support young people aged 1218 years to promote their mental wellbeing. 


\section{RELATED WORK}

$\mathrm{HCl}$ research on mental health has mostly focused on design to support the treatment of mental health problems. For example, studies include a computer game implementing Cognitive Behavioural Therapy (CBT) designed to support face-to-face clinical interventions with young people experiencing problems including depression and anxiety (Coyle et al. 2011); and a moderated online therapy and social networking website designed for young people recovering from First-Episode-Psychosis (FEP) (Lederman et al. 2014; Wadley et al. 2013). Studies that seek to promote mental wellbeing have received less attention. Thieme et al. suggest this is partly due to the concept of, and strategies to design for, mental wellbeing being less well understood both in healthcare and $\mathrm{HCl}$; but note that the need to gain a better understanding of mental wellbeing and how to design explicitly for it has become an increasing concern in $\mathrm{HCl}$ research on mental health (Thieme et al. 2015).

\subsection{Technology to Promote Mental Wellbeing}

This section presents examples of work involving design of technology to promote mental wellbeing.

'Spheres of Wellbeing' involved the design, deployment and evaluation of technology (Spheres) for a group of women experiencing a Learning Disability and Borderline Personality Disorder (Thieme et al. 2016). The premise for the project is that mental health interventions require treatment of any mental health problem and promotion of mental wellbeing, to prevent relapse or the onset of mental health problems. Accordingly, the Spheres aimed to both support the treatment of the women and promote their mental wellbeing. The latter through practices of mindfulness, and helping the women tolerate emotional distress and strengthen their sense of self. The Spheres were evaluated as having a positive impact on the mental wellbeing of the women, and hospital staff considered the Spheres a useful addition to existing services (Thieme 2015). However, as the project involved people aged 18+ years, its generalisability of findings to young people is limited.

'Innovation Labs' involved design and development of digital technologies to improve young people's mental health, with young people aged 16-25 years (Innovation Labs n.d.). Seven apps and websites were launched as part of the project: two of which are included in our review of digital technologies for supporting young people to promote their mental wellbeing (In Hand and Moodbug). An independent evaluation was conducted on five of the technologies using website traffic analytics, which showed evidence of good usage and engagement (Simons et al. 2015). Two technologies were further evaluated using a survey scale based on the Short Warwick-Edinburgh Mental Wellbeing Scale: most respondents thought that the technologies had helped them with their mental wellbeing across most of the dimensions measured in the scale. However, the project involved older young people (16-25 years) and the main target audience was young people with experience of mental health problems, rather than a universal population (i.e. all young people).

'Ginsberg' is a Scottish Government project to develop a web-based platform for delivering mental health services. The core product is an activity and mood diary that helps individuals identify sources of stress and anxiety, and monitor the impact of changes made to their behaviour and lifestyle (Scottish Government n.d.). Ginsberg is also included in our review of digital technologies. The project is driven by the Mental Health Strategy for Scotland (2012-15), which outlines a range of key themes to ensure improved services and outcomes for individuals and communities, including the effective use of technology (Scottish Government 2012). The Strategy recognised that many people already use the Internet and other new media approaches for help when they are in distress and that this trend is likely to increase over time. However, Ginsberg was not designed specifically for young people, and to date, there is no evidence of its effectiveness (Leigh \& Flatt 2015).

'Positive Computing' refers to the design of technology to support wellbeing. Calvo and Peters observe three categories of positive computing: preventative, active and dedicated (Calvo \& Peters 2013). Preventative technologies treat barriers to wellbeing, such as bullying, as 'errors' leading to a redesign of the technology. Active technologies involve adding specific features to promote wellbeing, such as a 'thanks' button on the basis that expressing gratitude improves overall wellbeing. Dedicated technologies promote a factor(s) of wellbeing such as mindfulness - two mindfulness apps are included in our review of digital technologies (Headspace and Smiling Mind). Calvo and Peters propose that the impact of 'dedicated' technologies is limited, as people need to be willing to find and use them. Instead, that the greatest impact will come when design and evaluation for wellbeing is an integral part of the design process of our day-to-day technological experiences.

\section{METHOD}

The purpose of this study was to explore the area of technology for promoting mental wellbeing in young people. The research was in two parts. First, the views of young people aged 12-18 years were gathered on the topic of digital technology for promoting mental wellbeing. A key finding was that participants indicated a preference for digital 
sources of support for mental health, but a limited knowledge and use of what is available. Next, therefore, a review was conducted of digital technologies designed to support young people aged 12-18 years to promote their mental wellbeing.

\subsection{Part 1: Focus Group Research}

A focus group research method was employed to gather the young people's views, where participants are selected on the basis that they would have something to say on the topic, are within the age-range, have similar sociocharacteristics and would be comfortable talking to the interviewer and each other (Rabiee 2004). The focus group was repeated with six groups of young people from a secondary school in North East Scotland: one group per school year (S1-S6). Each focus group was held within the School and lasted 55 minutes. In total, 34 young people (22 female, 12 male) participated (Table 2). Five focus groups were audio recorded: not everyone in the remaining group (S3) had parental consent for audio recording. The research data was analysed using the six phases of thematic analysis developed by Braun and Clarke (Braun \& Clarke 2006). This involved transcription and familiarisation with the data, generating initial codes, searching for themes, reviewing themes, defining and naming themes, and producing a report, which was validated by a sample of research participants.

Table 2: A total of 34 young people aged 12-18 years participated in the focus groups.

\begin{tabular}{|c|c|c|}
\hline Year & Age & No. Participants \\
\hline S1 & $12-13$ & 6 (2 female, 4 male) \\
\hline S2 & $13-14$ & $8(4$ female, 4 male $)$ \\
\hline$S 3$ & $14-15$ & 6 (6 female) \\
\hline$S 4$ & $15-16$ & 4 (4 female) \\
\hline$S 5$ & $16-17$ & $5(3$ female, 2 male $)$ \\
\hline$S 6$ & $17-18$ & $5(3$ female, 2 male $)$ \\
\hline
\end{tabular}

\subsubsection{Discussion: What Do You Think?}

The focus group started with a group discussion about mental health facilitated using three broad statements: 'very few people have mental health problems', 'people should talk openly about mental health problems' and 'a mentally healthy person is always happy'. A continuum was marked on the floor with 'strongly agree' and 'strongly disagree' as the extremes. After each statement was read out, participants were asked to stand in the spot on the continuum that represented their opinion about the statement and share their point of view with the group. At the end of the discussion, participants were given the opportunity to change their position on the continuum.

\subsubsection{Questionnaire: Sources of Support}

Next, an illustrated questionnaire was administered that asked: 'Where would you seek help from if you or a friend was struggling?' The purpose of the questionnaire was to explore participants' preferences for and knowledge of sources of support, given that it is not always possible to enjoy good mental health. Eight options were given: 'family', 'friend', 'doctor', 'teacher or school staff', 'library or bookshop', 'app or website', 'helpline', 'religious or spiritual community', 'youth group helper' and 'other'. Participants were asked to put a sticky dot against their preferred choices, specify 'app or website' and 'other' (if applicable) and briefly explain why they did or did not opt for each source of support.

\subsubsection{Discussion: Technology for Mental Wellbeing} Then, a group discussion about digital technologies for promoting mental wellbeing was facilitated and illustrated using promotional videos for two apps: Ginsberg and In Hand (In Hand n.d.). As described in the Related Work section, Ginsberg is an activity and mood diary. In Hand is a tool that proposes different activities according to how people feel, such as writing down their feelings or talking to someone, reading inspirational quotes or viewing photos. Prompted by the facilitators, participants discussed their initial impressions of the features, functionality and visual design of the apps. Participants also discussed other apps for mental wellbeing that they and their peers used.

\subsection{Part 2: Review of Digital Technologies}

A review method was employed to obtain a picture of digital technologies for supporting young people aged 12-18 years to promote their mental wellbeing. Due to time constraints, a limited search strategy was used. We searched two sources. The main source was Aye Mind. Aye Mind is a EUfunded project led by a NHS Board in Scotland as part of its strategy to promote child and youth mental health. The project website includes a directory of digital technologies identified, though not endorsed, by the Aye Mind team to support young people's mental health (Aye Mind n.d.). The second source was NHS Choices, which includes a more limited directory of online mental health services approved for use by NHS England (NHS Choices 2015). We also folded in a list of technologies that had been made available to young people at the secondary school where we conducted the focus groups, and technologies that the focus group participants reported that they and some of their peers used.

In total, 67 digital technologies were collected for possible inclusion in the review-four of which were provided by more than one source. The inclusion criterion for the review was technologies with a primary purpose of promoting mental wellbeing. The exclusion criteria was technologies targeted at people aged less than 12 years or more than 18 years. Each technology identified as promoting 
mental wellbeing in young people aged 12-18 years was reviewed in detail and in terms of engagement, usability, aesthetics and effectiveness. Finally, the Child and Adolescent Mental Health Service (CAMHS) in our area reviewed and validated the findings. CAMHS are specialist NHS services that help children and young people who have mental health problems.

\section{RESULTS AND DISCUSSION}

\subsection{Part 1: Focus Group Research}

Five themes were defined from the thematic analysis of the focus group research:

1. Apps and websites for mental wellbeing.

2. Stigma attached to mental health problems.

3. Differences in preferred ways of coping.

4. Confidentiality and trust.

5. School education on mental health.

Before discussing each of the themes, the specific results of the questionnaire are briefly presented. Twenty-seven $(79 \%)$ participants preferred 'app or website' as a source of support for mental health. After which, 26 (76\%) participants chose 'family' and 'friend'; 20 (59\%) chose 'doctor'; 17 (50\%) chose 'teacher or school staff'; $16(47 \%)$ chose 'helpline or helpdesk'; $11(32 \%)$ chose 'library or bookshop' and 'other'; 10 (29\%) chose 'youth group helper'; and three (9\%) chose 'religious or spiritual community' (Table 3). Only two sources of support were specified for 'other': talking to a pet and writing a diary. It is possible that participants' stated preference for digital sources of support was influenced by the topic of the focus group (digital technology for promoting mental wellbeing). However, other studies, involving significantly larger groups of young people, have also found a preference for 'app or website' as a source of information and support cf. (Office of the Children's Commissioner 2015; Young Minds 2014). The few qualitative responses given for preferring or not preferring apps or websites included easily accessible information and online chat with a professional, or conversely, a lack of knowledge about what is available and difficultly navigating some websites.

\subsubsection{Theme 1: Apps and Websites for Mental Wellbeing}

I wouldn't use [In Hand] because if I say I'm not feeling good then all its saying is 'well, feel better'. That's not very useful is it? (S4)

How do you know these online communities [social networking sites] are safe? (S5)

It's easier to use online resources. I would feel insecure about taking books out. (S6)
Table 3: Number of participants who reported that they would seek help from each source of support.

\begin{tabular}{|c|c|c|c|c|c|c|c|c|c|}
\hline & \multicolumn{9}{|c|}{ Sources of Support } \\
\hline 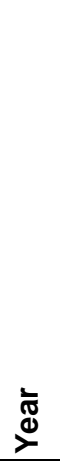 & $\begin{array}{l}\frac{0}{10} \\
\frac{0}{0} \\
\frac{0}{1} \\
\frac{1}{0} \\
\frac{0}{2} \\
\frac{0}{2}\end{array}$ & 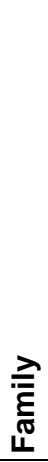 & 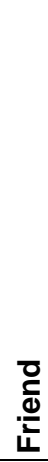 & 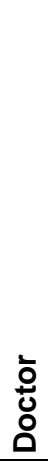 & 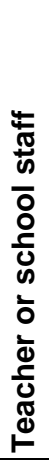 & 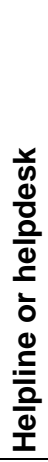 & 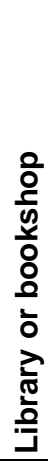 & 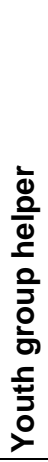 & 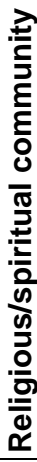 \\
\hline$S 1$ & 5 & 6 & 4 & 4 & 6 & 4 & 3 & 3 & 3 \\
\hline S2 & 7 & 8 & 5 & 6 & 6 & 5 & 1 & 4 & 0 \\
\hline S3 & 3 & 4 & 6 & 2 & 0 & 3 & 4 & 0 & 0 \\
\hline S4 & 4 & 3 & 4 & 1 & 1 & 1 & 2 & 0 & 0 \\
\hline S5 & 4 & 1 & 4 & 4 & 1 & 1 & 0 & 0 & 0 \\
\hline S6 & 4 & 4 & 3 & 3 & 3 & 2 & 1 & 3 & 0 \\
\hline & 27 & 26 & 26 & 20 & 17 & 16 & 11 & 10 & 3 \\
\hline
\end{tabular}

In all but one focus group, all or nearly all of the young people reported that they would most prefer to seek help and support from an app or website if they or a friend were struggling with their mental health. Some young people reported that they searched on Google or YouTube. For example, a participant from S6 commented 'Google search and I would follow the links to find the advice I need.' One website and two apps specifically for mental wellbeing were mentioned: the S1, S2 and S6 groups mentioned the well-established Childline website and Ask Sam problem page provided by the National Society for the Prevention of Cruelty to Children (NSPCC); and the S3, S4 and S5 groups discussed the Silent Secret and TalkLife social networking apps, which some reported that they and some of their peers use. In fact, TalkLife is targeted at people aged 17+ years and should therefore not be used by young people at S3 and S4 level. Some participants discussed the benefits and dangers of social networks. For example, young people are encouraged to open up and talk about their feelings, which can promote mental wellbeing. However, there is a risk of misinformed advice and bullying when sharing sensitive information with non-professionals, even though moderation is typically in place to protect users.

\subsubsection{Theme 2: Stigma Attached to Mental Health Problems}

If you talk openly to, say a friend, they might go and tell other people and then you would get picked on. (S1) 
If you have a mental health problem, you're almost 'bad' in a way, it's not natural almost. (S2)

If you've got a broken leg, you go around saying 'I've got a broken leg', but you won't go around saying 'I've been diagnosed with depression.' (S5)

Stigma attached to mental health problems was identified as a prominent theme in all focus groups. The groups discussed people concealing or not talking openly about mental health problems for a variety of reasons including: not wanting to upset friends / disappoint parents / create a fuss; the risk of being perceived as attention- or sympathyseeking; concerns over being judged or treated differently; and fear of being bullied. Across most year groups, most participants agreed that people should talk openly about mental health problems. Commonly cited benefits included that it can be a positive way of coping with problems, and it may also break down stigma surrounding mental health. A participant from S2 described a 'wall' that young people need to overcome in order to open up, because of a 'panic' about being judged by other people. A participant from S5 commented 'It's a "don't ask don't tell" sort of thing. It [mental health] has become shunned upon, looked down upon, and people get belittled and degraded.'

However, participants in the S3 and S4 groups disagreed or were neutral towards the statement that people should talk openly about mental health problems. The main reason given was that people have different ways of coping and should not feel under pressure to talk openly about mental health problems if they do not wish to do so. This viewpoint may be reflected in the results of the questionnaire, which found that the S3 and S4 groups preferred fewer sources of support (mean=4) compared to the other groups (mean=6 for years $\mathrm{S} 1$ and $\mathrm{S} 6$, and mean=5 for years S2 and S5).

\subsubsection{Theme 3: Differences in Preferred Ways of Coping}

People should talk and get help, but others can sometimes create so much fuss and try to help as much as they can that the person feels so much worse about their problem. (S2)

I would just try and keep it to myself until eventually it [problem] went away, because it's not going to be there forever. I wouldn't want to bother anyone about it. (S4)

What suits one person might not suit another. (S6)

Across most focus groups, particularly the $\$ 3$ and S4 groups, participants highlighted the importance of having freedom to choose how they cope with problems. In particular, sorting problems out on their own and not seeking help. This supports previous research that identified young people prefer to rely on themselves during difficult times and tend not to seek professional help (Bradford \& Rickwood 2014). However, while this approach may build capacity to self-manage problems, an increasing reluctance to seek professional support is associated with an increase in mental health problems (Bradford \& Rickwood 2014).

The results of the questionnaire found that there was no single source of support that all participants would opt for. Rather, participants selected a mix of options (range: 2 to 10) for a variety of reasons. For example, a participant from S4 commented that they would seek comfort from their dog because 'He won't judge me and he's great to hug.' A participant from S6 commented that they would seek help from a friend because 'They are usually partially aware of the situation and so can offer specific advice.' The results suggest that the maximum benefit to young people will come from strengthening the connectedness between digital and face-to-face sources of support, rather than stand-alone apps and websites.

\subsubsection{Theme 4: Confidentiality and Trust}

Most people, if they were going to speak to someone, like a doctor, would first go to someone they felt comfortable talking to. But some people don't feel that they have someone they can talk to, so they don't talk about it with anyone. (S4)

You should keep things to people you trust and fight with whatever your suffering with the people you trust. Might get through it easier. (S5)

When people find these kind of apps on your phone, it's like 'oh, why have you got that?' (S5)

Across most focus groups, participants discussed the importance of having confidence and trust in any individual that they choose to open up to with a problem. The results of the questionnaire found that seeking help from a doctor or member of school staff were less preferred courses of action, particularly among the S3 and S4 year groups. The qualitative responses given for not selecting these sources of support included fear of the young person's family or peers finding out, a perception of adults not genuinely listening, and concerns about being treated differently at school. For example, a participant from S5 commented 'If I say that I have an anxiety disorder, does that mean that teachers aren't going to ask me to do anything, or are they going to look down on me or not treat me as before?' Elsewhere, it has been reported that children do not have confidence in their doctor or school nurse when it comes to mental health, and 
are instead seeking advice on the Internet or from their friends (Richardson 2015).

Participants also discussed the importance of confidentiality with respect to digital technologies for mental wellbeing. In particular, they discussed password protection to prevent others accessing their accounts and viewing their activity. Some participants felt that having an app on their smartphone might draw unwanted attention, particularly if the icon (image and title) carried a connotation of mental health. Other researchers have reported how the title of their application (Mobile Mood Diary) meant that some of their adolescent participants did not install it on their phone since they were afraid their friends would see it, even though a Personal Identification Number (PIN) protected it (Doherty et al. 2010).

\subsubsection{Theme 5: School Education on Mental Health}

At least a couple of us [in the focus group] will be affected by mental health problems at some point in our lives. (S2)

A lot of people have mental health problems, but don't understand what is happening to them. (S3)

It's so hard to understand what other people are going through if you don't know what it feels like, and if you want to help someone you don't know how. (S5)

In all focus groups, there was a good level of awareness of the prevalence of mental health problems. In some groups, participants stated that education around mental health should begin at an early stage and cover a broader range of information. For example, they raised concerns about not recognising mental health problems, which is indeed a major filter to help-seeking (Rickwood et al. 2007), and limited knowledge of how to respond to friends experiencing mental health problems. A participant from S5 commented that they would avoid the topic for 'Fear of making it worse' if a friend confided in them. This is significant as the results of the questionnaire found that almost four out of five young people would seek help from a friend if they were struggling, indicating the value of supportive and knowledgeable peers. The young people also discussed the importance of education on mental health for parents, as well as adults who work to support the learning of young people such as teachers and school nurses.

\subsection{Part 2: Review of Digital Technologies}

All of the 67 digital technologies collected for possible inclusion in the review were either an app, with or without a web version, or a website. Of these, only 14 (21\%) were identified as having a primary purpose of supporting young people aged
12-18 years to promote their mental wellbeing (Table 4). This percentage illustrates that while there is an increasingly high volume of apps and websites targeted at mental health, a relatively small proportion are focused on promotion. Seven of the 14 technologies included in the review are directly targeted at young people aged 12-18 years inclusive - the age limits of the individual apps and websites varied e.g. 11-19 years, 11-26 years and under 19 years. Of the remaining seven technologies, two have no age limits, one is targeted at 13-25 year olds, three are targeted at 16-25 year olds, and one is targeted at young people aged $17+$ years. Just one of the technologies (Smiling Mind) offers tailored programmes for different age groups of young people including 12-15 years and 16-22 years.

All of the digital technologies included in the review were considered to be helpful in supporting young people to promote their mental wellbeing and, for the most part, highly usable and visually appealing with appropriate language. Some of the good information on a few websites (Childline, The Mix and Young Scot) was harder to find. However, limitations were identified: a lack of practical tools within the information-based websites, a lack of practical tools within several of the apps, and a lack of information on mental health within all of the apps. The provision of practical tools is important to support young people to translate what they are reading into exercises that they can experience and use in times of need. To our knowledge, only two of the apps have thus far been evaluated for effectiveness: Headspace (Howells et al. 2016) and In Hand (Simons et al. 2015), which is consistent with reports of a high availability of apps but low evidence base of effectiveness (Leigh \& Flatt 2015).

For example, as noted, Ginsberg is an activity and mood diary that helps individuals identify sources of stress and anxiety, and monitor the impact of changes made to their behaviour and lifestyle. However, it does not provide immediately accessible suggestions of strategies that could be employed to address the identified issue. It is therefore essential that the user has prior knowledge-or can find out from an alternative source-what type of changes would be effective and how to make them. Similarly, SafeSpot promotes the development of positive strategies for coping with adverse life events by encouraging young people to create a personalised list of coping skills. However, it does not provide any practical information within the app to generate the list and so relies on the young person having external knowledge of different coping skills and how to put them into practice. SafeSpot also does not provide any information on mental health within the app.

Another example is In Hand, which suggests activities to help young people in a moment of 
Table 4: Fourteen apps and websites were identified as supporting young people aged 12-18 years to promote their mental wellbeing.

\begin{tabular}{|c|c|c|}
\hline Resource & Brief Description & App/Website \\
\hline Ginsberg & $\begin{array}{l}\text { Activity and mood diary to help people identify triggers that affect their mood and } \\
\text { stress levels, and monitor the progress of changes to their lifestyle. }\end{array}$ & $A p p$ \\
\hline In Hand & $\begin{array}{l}\text { A simple tool to help in a moment of stress or low mood. Asks the question 'hello, } \\
\text { how are you feeling?' and suggests different activities. }\end{array}$ & App \\
\hline Moodbug & $\begin{array}{l}\text { Social network game created from phone contacts to share mood and energy levels } \\
\text { with friends, and send virtual gifts. Includes a mood tracker. }\end{array}$ & $A p p$ \\
\hline SafeSpot & $\begin{array}{l}\text { A tool to create a personalised list of coping skills and emergency contacts. } \\
\text { Includes audio clips of relaxation exercises and a map of local services. }\end{array}$ & App \\
\hline Silent Secret & $\begin{array}{l}\text { A social support network for anonymously sharing secrets, feelings and thoughts. } \\
\text { Includes interaction buttons: 'heart', 'me2' and 'hug'. }\end{array}$ & App \\
\hline Childline & $\begin{array}{l}\text { Information on a range of topics including mental health. Includes support from } \\
\text { Childline counsellors through Ask Sam (letter writing), online chat and email. }\end{array}$ & Website \\
\hline ReachOut.com & $\begin{array}{l}\text { Information, advice and support on mental health. Available in Australia, Ireland and } \\
\text { the US. Includes forums and emergency support information. }\end{array}$ & Website \\
\hline The Mix & $\begin{array}{l}\text { Information on a range of topics including mental health. Includes a local services } \\
\text { directory and support from The Mix advisors through online chat and email. }\end{array}$ & Website \\
\hline YoungMinds & $\begin{array}{l}\text { Information and advice on mental health. Includes information about medication, } \\
\text { campaigns and campaign packs, real stories, and a guide to mental health services. }\end{array}$ & Website \\
\hline Young Scot & $\begin{array}{l}\text { Information on a range of topics including mental health. Includes a local services } \\
\text { directory and a support services listing. }\end{array}$ & Website \\
\hline Headspace & $\begin{array}{l}\text { Mindfulness meditation programmes. Includes a progress tracker (graphs), a buddy } \\
\text { system, rewards (based on usage), and daily reminders/messages. }\end{array}$ & $\begin{array}{l}\text { App \& web- } \\
\text { based }\end{array}$ \\
\hline Smiling Mind & $\begin{array}{l}\text { Mindfulness meditation programmes for different age groups. Includes a progress } \\
\text { tracker (graphs) and record of programmes/sessions started or completed. }\end{array}$ & $\begin{array}{l}\text { App \& web- } \\
\text { based }\end{array}$ \\
\hline Stressheads & $\begin{array}{l}\text { Game to understand and manage stress. Links to The Mix website, and other } \\
\text { websites, for information on the category of stress chosen in the game. }\end{array}$ & $\begin{array}{l}\text { App \& web- } \\
\text { based }\end{array}$ \\
\hline TalkLife & $\begin{array}{l}\text { Social support network for sharing personal problems or struggles, anonymously or } \\
\text { by name. Includes interaction buttons: 'support', 'hug', 'OMG' and 'same'. }\end{array}$ & $\begin{array}{c}\text { App \& web- } \\
\text { based }\end{array}$ \\
\hline
\end{tabular}

stress or low mood. The app is intended as a simple tool with a specific, focused purpose. However, it neither provides practical tools to help the young person better understand their feelings nor information on mental health. By contrast, YoungMinds and ReachOut.com provide a great deal of useful information on mental health including medication and real stories (YoungMinds) and information on a broader range of topics such as physical health, alcohol and other drugs (ReachOut.com). However, neither website provides immediately accessible practical tools to support young people to apply the information they have read.

Despite the increasing recognition of schools as important settings for promoting mental health in young people, for the most part, the apps and websites sampled in the review do not explicitly link with school learning in mental health. This is an important gap in design. Only two of the apps have an associated school programme: SafeSpot and Smiling Mind. Alongside the SafeSpot app, the SafeSpotter Programme trains selected older students to be first points of contact in schools for younger people experiencing mental health problems, as an alternative to approaching an adult. Alongside the Smiling Mind app, the Smiling Mind Education Programme is a series of age specific lesson plans mapped to the Australian Curriculum that can be used to support existing wellbeing, pastoral care and training. Two of the information-based websites included in the review, ReachOut.com and YoungMinds, offer courses and resources for education professionals.

\section{OPPORTUNITIES FOR DESIGN}

This section presents four areas of opportunity for future research and design to support young people aged 12-18 years to promote their mental wellbeing, translated from the research findings of the focus groups and the review:

1. Improve the design of digital technologies.

2. Reinforce school learning in mental wellbeing.

3. Design a directory of digital technologies.

4. Provide support for different age groups.

\subsection{Improve the Design of Digital Technologies for Promoting Mental Wellbeing}

Overall, the results of this study demonstrate huge potential for $\mathrm{HCl}$ research and design in the area of digital technologies for promoting mental wellbeing. The findings of the review indicate that a relatively limited number of apps and websites are directly targeted at supporting young people aged 12-18 years to promote their mental wellbeing. Further, limitations were identified with the technologies sampled, which could be improved upon in future designs: a lack of practical tools within the 
information-based websites, a lack of practical tools within several of the apps, a lack of information on mental health within all of the apps, and limited evaluation for effectiveness.

Practical tools: Practical tools are important to support young people to translate what they are reading into exercises/mechanisms that they can experience and use in times of need. What these practical tools might look like is dependent on the purpose and target outcomes of the particular app or website. However, to illustrate the point, the In Hand app included in the review is designed to help in a moment of stress or low mood. It incorporates a basic tool for listening to music, which should be helpful, given that music listening has been directly linked to mood improvement (Bakker et al. 2016). However, the app design could be improved by incorporating a practical tool to help young people understand the factors that affect their mood and stress levels.

Information on mental health: Providing information on mental health is important. For example, it can improve understanding about mental health, which in turn is associated with a reduction in stigmatising beliefs about those with mental health problems, and an increase in help-seeking (Bakker et al. 2016). A simple solution to the lack of information on mental health within the apps included in the review, is to provide access to an information website. For example, the Stressheads app included in the review links to articles on its developer's website (The Mix) as well as other websites for information on mental health.

Evaluating effectiveness: Evaluating effectiveness is important to support young people, and adults working with young people, to make a judgment about what is a high quality app or website. The Nominet Trust, the UK's leading social tech funder, proposed a progressive approach to evaluation: in its paper 'lean social metrics', appropriate metrics are mapped against the development stages of a technology (Sutch \& Kirkland 2014). For example, the discovery phase will likely include interviews and co-design and prototyping sessions; the development phase will likely include movement against established scales, such as the WarwickEdinburgh Mental Wellbeing Scale and web analytics; and the ongoing task of scaling will likely include a randomised controlled trial (RCT).

Further, while several of the technologies reviewed are focused on the same factors of wellbeing-e.g. there are two mindfulness apps (Headspace and Smiling Mind) and three social networking apps (Moodbug, Silent Secret and TalkLife)-there are some noticeable gaps. Such as, design to promote regular physical activity, which is associated with a greater sense of wellbeing across all age groups (New Economics Foundation 2008). Effective apps promoting physical activity have already been developed, but lack an explicit link to mental health (Bakker et al. 2016). There is also an opportunity to establish specific design guidelines, recommended by Doherty et al. (Doherty et al. 2010), for the specific area of secondary school-aged young people and mental health promotion.

\subsection{Reinforce School Learning in Mental Wellbeing}

Schools are becoming the main setting for mental health promotion in children and young people. However, only one of the apps and websites included in the review (Smiling Mind) explicitly links with school learning in mental health. This indicates an underexplored opportunity for design in $\mathrm{HCl}$ to reinforce school learning in mental wellbeing. In other words, to build on or leverage the knowledge and understanding etc. that young people should be developing at school from one stage or level of learning to another, as opposed to designing a stand-alone technology. Additionally, there is an opportunity for capacity building of adults who work with young people, such as teachers and school nurses, to deliver aspects of school curriculums that are their responsibility. For example, in Scotland, this would involve aligning with Curriculum for Excellence experiences and outcomes in mental and emotional wellbeing. These include: understanding the importance of mental wellbeing, promoting personal coping skills and positive relationships, and knowing where to get support if needed. A useful starting point could be to research what schools are delivering, and how, in relation to teaching and learning in mental wellbeing. This opportunity is aligned with other $\mathrm{HCl}$ research work that identified opportunities for design of digital technology to augment the learning of social and emotional skills in schools (Slovak et al. 2015).

\subsection{Design a Directory of Digital Technologies for Mental Wellbeing}

The focus group findings identified a preference among the young people for digital sources of support, but a limited knowledge and use of what is available - this limited knowledge extended to some School staff. This is important because young people are more inclined to seek help for mental health problems if they are knowledgeable about sources of help (Rickwood et al. 2007). However, a limited knowledge of digital technologies for mental wellbeing is perhaps not surprising, given there is no official directory in Scotland or the UK. The most established directories for apps are Apple iTunes and Google Play stores where there is little information to support a judgment about what is appropriate and high quality, other than star ratings and user reviews, which are subjective by nature and may come from suspicious sources (Stoyanov et al. 2015). This presents a challenge to young 
people and adults working with young people, such as teachers and school nurses, and it is a challenge that extends to websites. The Children's Commissioner for England has noted that while there are some good websites for mental health, it is a 'matter of luck' whether children find them (Richardson 2015).

There is therefore an opportunity to design a directory of high quality digital technologies to support young people aged 12-18 years to promote their mental wellbeing. The ReachOut.com (Australia) website included in the review provides a model for consideration. It includes a directory of apps for heath and wellbeing called The Toolbox. Each app is reviewed for quality by a health professional(s) and young person(s) using the MARS (Mobile App Rating Scale) and uMARS (Mobile App Rating Scale: User Version) tools (Stoyanov et al. 2015; Stoyanov et al. 2016). The Toolbox is designed to help young people find apps that will achieve their goals through taking a quiz: a list of apps is recommended based on the answers (goals) they select. The Toolbox is currently being evaluated in a randomised controlled trial with older young people aged $16-25$ years.

In designing a directory, an important consideration is how young people understand the concept of mental health, the language that they use, and how this guides their reasoning in relation to use of digital technologies. As touched upon at the start of this paper, the terminology of mental health is subject to considerable debate, in part due to the different models of mental health (e.g. medical, biopsycho-social, social). Consequently, a range of terms and definitions are used and their use is often inconsistent. This inconsistency can and does lead to a lack of clarity and confusion about what exactly is being referred to. NHS Health Scotland, whose terminology we have adopted, accepts that children and young people may use a different language. However, there has been little research to date on this topic, and if/how the language used by young people to search for apps and websites varies by age, gender, class, or ethnicity.

\subsection{Provide Support for Different Age Groups}

Increasingly, individuals are being encouraged to take personal responsibility for their own health and wellbeing. However, there is a link between an increasing inclination by young people to not seek professional support as they progress through adolescence and an increase in mental health problems (Bradford \& Rickwood 2014). Notably, in Scotland, the mental health of boys and girls tends to decline from S2 to S4 (NHS Health Scotland 2015). The focus group findings identified differences between the young people in the middle year groups (S3 and S4) compared to the other year groups, with respect to talking openly about mental health problems and seeking professional support. This difference highlights an opportunity for further research with a larger number of participants, comparing the attitudes and preferences of individual secondary school year groups towards promoting their mental wellbeing. The apps and websites included in the review mostly approach 'young people' as a homogenous group: only one app (Smiling Mind) offers agespecific content. Identification of issues common to all year groups or distinct to particular year groups can inform the design of technology that best engages and supports all young people aged 1218 years. As a participant in the S5 group put it ' $A$ first year will feel different to how a sixth year feels.'

\section{CONCLUSION}

Mental health problems can significantly affect young people's educational and social development, and problems tend to persist into adulthood. Mental health promotion aims to elevate levels of mental wellbeing and help prevent relapse or onset of mental health problems. To our knowledge, this study provides the first review of apps and websites for promoting mental wellbeing in young people aged 12-18 years, and demonstrated the need and potential for $\mathrm{HCl}$ research and design in this space. The presented findings were translated into four areas of opportunity for future work: improve the design of digital technologies by providing practical tools and mental health information and establishing evidence of effectiveness (where lacking); reinforce school learning in mental wellbeing by linking with school curricula; design a directory to support young people (12-18 years) to find high quality apps and websites for promoting mental wellbeing; and provide support for different age groups by better understanding any differences in attitudes and preferences towards mental health promotion. Overall this work is intended to offer inspiration to design for mental wellbeing.

\section{LIMITATIONS}

Limitations of the focus group research were the relatively small sample size of young people and possibility of self-selection bias. A limitation of the review is that it did not involve exhaustive, comprehensive searching. Also, there is a grey area between promotion and prevention and so the sifting process was to a limited extent subjective.

\section{ACKNOWLEDGEMENTS}

We thank all those who were involved for their time and support, with special thanks to Ainsley James and Sorcha Ni Chobhthaigh. The Mental Health Innovation Fund funded the review. 


\section{REFERENCES}

Aye Mind Positive about wellbeing. Available from: http://ayemind.com/ [7 February 2016].

Bakker, D., Kazantzis, N., Rickwood, D. \& Rickard, N. (2016) Mental health smartphone apps: review and evidence-based recommendations for future developments. JMIR Mental Health, 3 (1). e7.

Bradford, S. \& Rickwood, D. (2014) Adolescent's preferred modes of delivery for mental health services. Child and Adolescent Mental Health, 19 (1). 39-45.

Braun, V. \& Clarke, V. (2006) Using thematic analysis in psychology. Qualitative Research in Psychology, 3 (2). 77-101.

Calvo, R.A. \& Peters, D. (2013) Promoting psychological wellbeing: loftier goals for new technologies [opinion]. IEEE Technology and Society Magazine, 32 (4). 19-21.

Clarke, A.M., Monreale, S. \& Field, C.A. (2015) What works in enhancing social and emotional skills development during childhood and adolescence? Available from: http://www.eif.org.uk/wpcontent/uploads/2015/03/Review-of-Socialand-Emotional-Skills-BasedIntervention_Report-WEB-VERSION.pdf [7 February 2016].

Coyle, David., McGlade, Nicola., Doherty, Gavin. \& O'Reilly, Gary (2011). Exploratory evaluations of a computer game supporting cognitive behavioural therapy for adolescents. Proceedings of CHI 2011. Vancouver, 7-12 May 2011. New York: ACM. 2937-2946.

Doherty, G., Coyle, D. \& Matthews, M. (2010) Design and evaluation guidelines for mental health technologies. Interacting with Computers, 22 (4). 243-252.

Education Scotland Experiences and outcomes health and wellbeing. Available from: https://www.education.gov.scot/Documents/h ealth-and-wellbeing-eo.pdf [7 February 2016].

GOV.UK Annual report of the chief medical officer 2013. Available from:

https://www.gov.uk/government/publications/c hief-medical-officer-cmo-annual-report-publicmental-health [7 February 2016].

Gulliver, A., Griffiths, K.M. \& Christensen, H. (2010) Perceived barriers and facilitators to mental health help-seeking in young people: a systematic review. BMC psychiatry, 10 (1). 113.

Howells, A., Ivtzan, I. \& Eiroa-Orosa, F.J. (2016) Putting the 'app' in happiness: a randomised controlled trial of a smartphone-based mindfulness intervention to enhance wellbeing. J Happiness Stud, 17 (1). 163-185.

In Hand Bringing balance to everyday life. Available from: http://www.inhand.org.uk/ [7 February 2016].

Innovation Labs Better mental health for young people. Available from:

http://www.innovationlabs.org.uk/ [7 February 2016].

Kessler, R.C., Amminger, G.P., Aguilar-Gaxiola, S., Alonso, J., Lee, S. \& Ustün, T.B. (2007) Age of onset of mental disorders: a review of recent literature. Current opinion in psychiatry, 20 (4). 359-64.

Keyes, C.L.M. (2014) Mental health as a complete state: how the salutogenic perspective completes the picture. In: Bauer, G.F. \& Hämmig, O. (eds). Bridging occupational, organizational and public health. Springer Netherlands. 179-192.

Lederman, R., Wadley, G., Glesso, J., Bendall, S. \& Álvarez-Jiménezm, M. (2014) Moderated online social therapy: designing and evaluating. ACM Transactions on ComputerHuman Interaction, 21 (1). 1-26.

Leigh, S. \& Flatt, S. (2015) App-based psychological interventions: friend or foe? Evidence-Based Mental Health 18 (4). 97-99.

Mental Health Foundation Fundamental facts about mental health 2015. Available from: https://www.mentalhealth.org.uk/publications/f undamental-facts-about-mental-health-2015 [7 February 2016].

Sutch, D. \& Kirkland, K. (2014) Lean social metrics Nominet Trust. Available from: http://www.nominettrust.org.uk/knowledgecentre/publications/lean-social-metrics [7 February 2016].

New Economics Foundation (2008) Five ways to wellbeing: the evidence. Available from: http://www.neweconomics.org/publications/en try/five-ways-to-well-being-the-evidence [7 February 2016].

NHS Choices Five steps to mental wellbeing. Available from: http://www.nhs.uk/conditions/stress-anxietydepression/pages/improve-mentalwellbeing.aspx [7 February 2016].

NHS Choices Online mental health services. Available from: http://www.nhs.uk/Conditions/online-mentalhealth-services/Pages/introduction.aspx [7 February 2016].

NHS Health Scotland (2010) Mental health improvement terminology and working 
understandings. Available from: http://www.healthscotland.com/documents/46 14.aspx [7 February 2016].

NHS Health Scotland Scottish mental health profiles for adolescents. Available from: http://www.healthscotland.com/documents/26 515.aspx [7 February 2016].

Ofcom Adults' media use and attitudes report 2016. Available from: https://www.ofcom.org.uk/research-anddata/media-literacy-research/adults-mediause-and-attitudes [7 February 2016].

Ofcom Children and parents: media use and attitudes report 2016. Available from: https://www.ofcom.org.uk/research-anddata/media-literacyresearch/children/children-parents-nov16 [7 February 2016].

Office of the Children's Commissioner (2015) Children need information about their mental health which they can trust, is accessible and part of everyday life - survey. Available from: http://www.childrenscommissioner.gov.uk/new s/children-need-information-about-theirmental-health-which-they-can-trustaccessible-and-part [7 February 2016].

Rabiee, F. (2004) Focus-group interview and data analysis. The Proceedings of the Nutrition Society, 63 (4). 655-660.

Richardson, H. (2015) Children seeking mental health advice on internet. BBC. Available from: http://www.bbc.co.uk/news/education34423949 [7 February 2016].

Rickwood, D.J., Deane, F.P. \& Wilson, C.J. (2007) When and how do young people seek professional help for mental health problems? The Medical Journal of Australia, 187 (7 Suppl). 35-39.

Scottish Government Ginsberg. Available from: https://www.ginsberg.io/ [7 February 2016]

Scottish Government (2012) Mental health strategy for Scotland: 2012-2015. Available from: http://www.gov.scot/Publications/2012/08/971 4/0 [7 February 2016].

Simons, L., Craven, M. \& Martin, J. (2015) Learning from the labs volume 2: evaluating effectiveness, lessons and reflections Innovation Labs. Available at: http://www.innovationlabs.org.uk/wpcontent/uploads/2015/04/Learning-from-theLabs-Volume-2-Evaluating-Effectiveness.pdf [7 February 2016].

Slovak, Petr., Gilad-Bachrach, Ran. \& Fitzpatrick, Geraldine (2015). Designing social and emotional skills training: the challenges and opportunities for technology support. Proceedings of $\mathrm{CHI}$ 2015. Seoul, 18-23 April 2015. New York: ACM. 2797-2800.

Stoyanov, S.R., Hides, L., Kavanagh, D.J. \& Wilson, H. (2016) Development and validation of the user version of the mobile application rating scale (UMARS). JMIR mHealth and uHealth, 4 (2). e72.

Stoyanov, S.R., Hides, L., Kavanagh, D.J., Zelenko, O., Tjondronegoro, D. \& Mani, M. (2015) Mobile app rating scale: a new tool for assessing the quality of health mobile apps. JMIR mHealth and uHealth, 3 (1). e27.

Thieme, Anja., McCarthy, John., Johnson, Paula., Phillips, Stephanie., Wallace, Jayne., Lindley, Siân., Ladha, Karim., Jackson, Daniel., Nowacka, Diana., Rafiev, Ashur., Ladha, Cassim., Nappey, Thomas., Kipling, Mathew., Wright, Peter., Meyer, Thomas D. \& Olivier, Patrick (2016). Challenges for designing new technology for health and wellbeing in a complex mental healthcare context. Proceedings of $\mathrm{CHI}$ 2016. Santa Clara, 7-12 May 2016. New York: ACM. 2136-2149.

Thieme, Anja., Wallace, Jayne., Meyer, Thomas. \& Olivier, Patrick (2015). Designing for mental wellbeing: towards a more holistic approach in the treatment and prevention of mental illness. Proceedings of British $\mathrm{HCl}$ 2015. Lincoln, 1317 July 2015. New York: ACM. 1-10.

Thieme, A. (2015) Designing technology to promote mental health and wellbeing. Available from: http://hdl.handle.net/10443/2864 [7 February 2016].

Wadley, Greg., Lederman, Reeva., Gleeson, John. \& Alvarez-Jimenez, Mario (2013). Participatory design of an online therapy for youth mental health. Proceedings of Australian CHI 2013. Adelaide, 25-29 November 2013. New York: ACM. 517-526.

Weare, K. \& Nind, M. (2011) Mental health promotion and problem prevention in schools: What does the evidence say? Health Promotion International, 26 (SUPPL. 1). i29i69.

World Health Organization (2013) Comprehensive mental health action plan 2013-2020. Available from: http://www.who.int/mental_health/action_plan _2013/en/ [7 February 2016].

Young Minds (2014) Report on children, young people and family engagement. Available from:https://www.gov.uk/government/uploads/ system/uploads/attachment_data/file/413411/ Young_Minds.pdf [7 February 2016]. 